\title{
Degree of Dental Attrition of the Kanenokuma Yayoi Population
}

\author{
HISASHI FUJITA \\ Department of Epidemiology, Tokyo Metropolitan Institute of Gerontology, \\ 35-2 Sakaecho, Itabashi-ku, Tokyo 173, Japan
}

Received October 5, 1992

\begin{abstract}
The degree of dental attrition of the Kanenokuma skeletal series, which are famous for the skeletons of the Yayoi type, were investigated. For comparative study, specimens which are in a good state of preservation have been assigned to age categories by the observation on some morphological features in the skeletal remains, and by using Tochihara's inspective method, they were compared with the dental attrition of modern Japanese which were examined by Tochihara in 1957. The results indicated that the dental attrition of the Kanenokuma population was pronounced in comparison with modern Japanese. Moreover, the degree of dental attrition was considerably useful for adult's age estimation when the standards of population-specific rates of functional dental attrition are assessed.
\end{abstract}

Key Words: degree of dental attrition, age at death, Kanenokuma population, Yayoi period

\section{INTRODUCTION}

Study of the degree of dental attrition has some merits in the fields of anthropology and forensic medicine. Especially, dental attrition is one of the most useful markers to estimate age at death. Given some standard diet, teeth of different individuals should wear at roughly the same rate. The degree of dental attrition should, therefore, represent the age of individuals.

This field of study was advanced by some workers (Campbell, 1939; Dobrovsky, 1949; Pederson, 1952; Zuhrt, 1955). After that, Miles (1963) completed a study of dental aging on early British materials and was the first to establish a scale of attrition based on molars development. Lovejoy (1985) and Lovejoy et al. (1985a) in the study on the Libben site, midwestern United States, emphasized that dental attrition assessed by seriation procedures is an excellent indicator of age at death. They both studied this problem by the theory which utilized phased eruption of three molars.

In Japan, there have been some studies in this area (Hada, 1936; Yamada, 1932; Hojo, 1959; Tsuda, 1952; Yoshida, 1976; Takei et al., 1981), but they are unsatisfactory since methods of judging the degree of dental attrition have not been sufficiently integrated so far. In other words, the methods and the data generated have been dependent only upon their own purposes. On the other hand, dental 
attrition is greatly influenced by the culture, including food, customs, subsistence and so on at the time. To use the dental attrition for age estimation, therefore, we must assess useful age-attrition standards for a group in accordance with materials belonging to specific period and specific area. In 1957, a Japanese anatomist, Tochihara, studied this problem by using quite enough materials of modern Japanese (510 individuals with age range of 20 to 83 years old) and established a welldesigned classification as shown in Table 1.

The purpose of this study is, by using Tochihara's classification and his results, to compare the degree of dental attrition between the Kanenokuma skeletons of the Yayoi period and modern Japanese skeletons, and to examine the relationship between age at death and the degree of dental attrition among Kanenokuma population.

Table 1. Tochihara's classification on dental attrition, in comparison with that of Broca.

\begin{tabular}{lcccc}
\hline & \multicolumn{2}{c}{ Tochihara } & & Broca \\
\cline { 2 - 3 } \multicolumn{1}{c}{ Degree of attrition } & & & Degree \\
\hline No wear & 1 & $\vdots$ & \\
Enamel-dots or lines & 2 & $\vdots$ & 1 \\
Enamel-plane or zonal & 3 & $\vdots$ & \\
Enamel-overall & 4 & $\vdots$ & \\
Dentine-dots or lines & 5 & $\vdots$ & 2 \\
Dentine-plane or zonal & 6 & $\vdots$ & \\
Dentine-overall & 7 & $\vdots$ & 3 \\
Extend to the neck & & & \\
\hline
\end{tabular}

\section{MATERIALS AND METHODS}

The skeletal materials were excavated in the 1960's to the 1980's from a burial site at Kanenokuma, which is located 8 kilometers northwest of Hakata Bay, Kyushu, Japan (Fig. 1). These specimens were mostly discovered from Yayoi burial jars, the so-called "Kame-kan," which is a characteristic of burial customs in the northern part of Kyushu. One hundred and thirty-seven individuals, from the infants to the aged, were discovered from the site and were housed in the Department of Anatomy, Faculty of Medicine, at Kyushu University. It is thought that they are typical immigrant human skeletons of the Yayoi period (ca. 300 B.C.- A.D. 300, Aeneolithic stage in Japan). Anthropological and anatomical features of their 

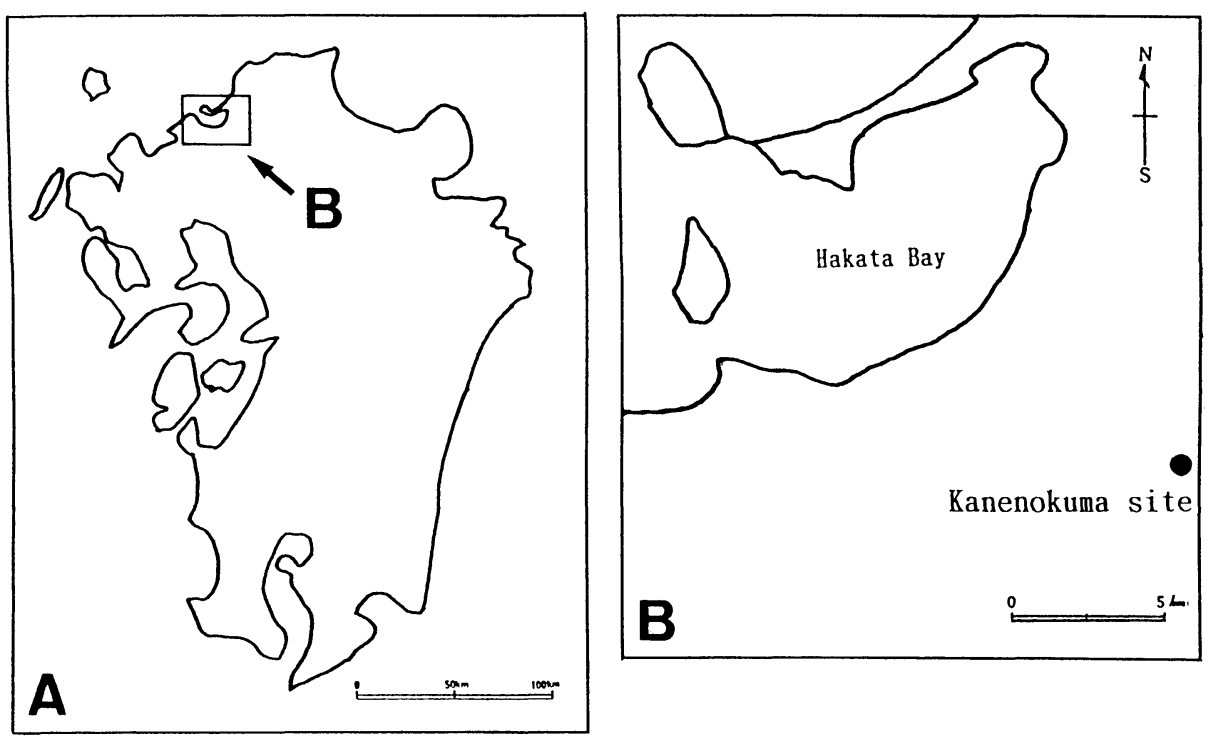

Fig. 1. Location of Kanenokuma site, Kyushu.

A: Map of Kyushu showing the area including Kanenokuma site.

B: Kanenokuma site.

skeletons were studied and published by Nagai $(1970,1971)$ and Nakahashi et al. (1985).

Inspective method of dental attrition followed that of Tochihara (1957). The present author adopted his classification (Table 1 and Fig. 2) in this study. The elucidation of the respective stages are as follows:

Stage 0: Unworn.

Stages 1, 2, 3: Judgment of the attritional condition of the facet's of the enamel, which take the figure of dots or lines (Stage 1), plane or zonal (Stage 2 ), or overall extent (Stage 3). The attrition of these three stages are restricted to the enamel only.

Stages 4, 5, 6: Judgment of the attritional conditions of the dentine, which also take the figure of dots or lines (Stage 4), plane or zonal (stage 5), or overall extent (Stage 6). Dentine exposure exists in these stages.

Stage 7: Wear extends into the neck.

The teeth of each skeleton were classified into the 8 stages one by one according to the standard of the dental attrition. Then the average score was calculated to the first decimal place. 


\section{Teeth Number}

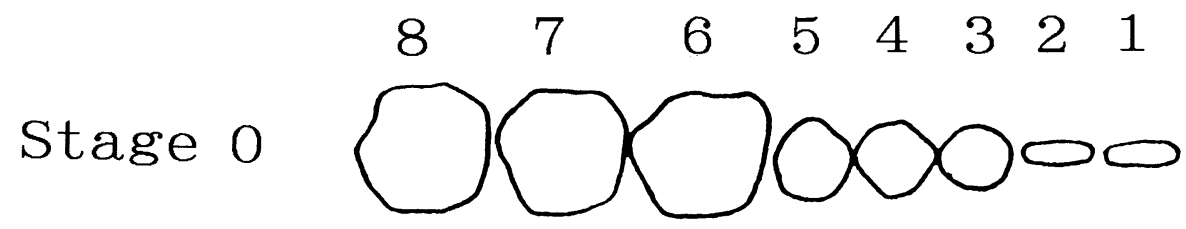

Stage 1

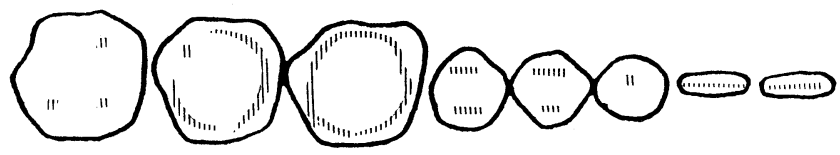

Stage 2

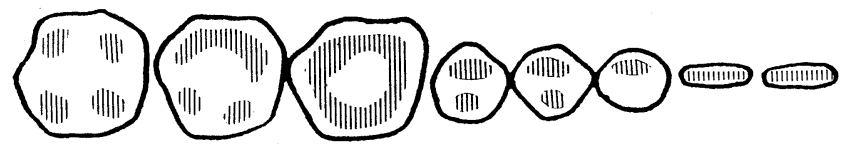

Stage 3

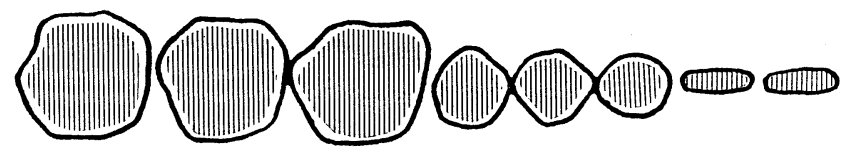

Stage 4

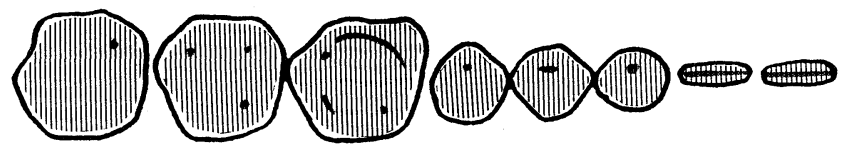

Stage 5

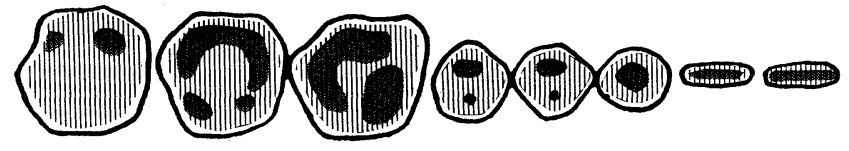

Stage 6

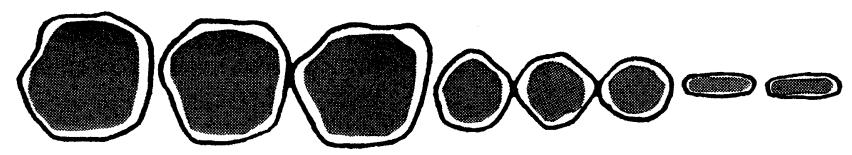

Stage 7

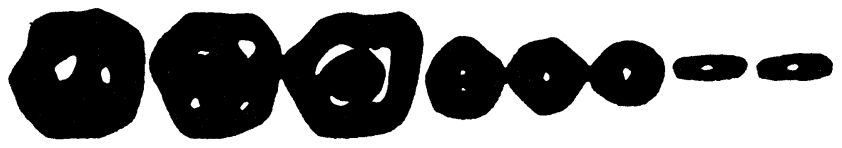

Fig. 2. Schematic representation on dental attritional condition defined in Table 1 . 
Sex determination followed the excavation report by Nakahashi et al. (1985). As the age of the Kanenokuma skeletons is unknown, direct comparison in the degree of dental attrition between those of Kanenokuma and modern Japanese is impossible. Accordingly, skeletal informations regarding the developmental ageassociated indicators were evaluated for age estimation. Several morphological indicators, such as cranial suture closure (Meindl and Lovejoy, 1985), pubic symphysis surface (Meindl et al., 1985; Hanihara, 1952), auricular surface of the ilium (Lovejoy et al., 1985b), epiphyseal closure (Mckern and Stewart, 1957), and dental development (Ubelaker, 1989) were utilized. Infant and subadult individuals were excluded, and the specimens which were approximately 20 years and over were selected and assigned to one of the three age groups, i.e., (1) ca. 20-29, (2) ca. 3039 , (3) ca. 40 and over, respectively.

The significance of differences between scores was examined by Student's $t$-test and differences giving $P<0.01$ were regarded as significant.

\section{RESULTS AND DISCUSSION}

Sixty-two specimens from among 137 were available for the observation of dental attrition. Only 26 specimens were available for age estimation on account of wellpreserved materials.

The degree of dental attrition of the 26 specimens is shown in Table 2. Table 3 shows the summary results of the degree of dental attrition according to the estimated age at death.

There is hardly any difference between the right and left sides, and the degree of dental attrition is almost the same between upper and lower teeth. There were no statistically significant differences in these matters.

With regard to the difference between the sexes, it is probable that males have stronger attrition than those of females in every age range. However, it has not been shown to be a significant difference. In Table 3, the degree of dental attrition of females is higher than that of males in the ca. 20-29 year-old-age range, but it is due to one specimen which has an extremely high degree of dental attrition, scored 4.7 (IDNO: K-56F., see Table 2.). In addition to this specimen, another specimen shows a striking attrition and a sharp contrast between right and left sides. It is supposed that these two specimens were in some kind of peculiar circumstance that forced them into extreme dental attrition.

The degree of dental attrition progresses at a roughly regular rate as the age advances (Fig. 3). If the three age classes are represented by the values 20, 30 and 40 years old for the purpose of calculation, it provides the high coefficients of correlation between the estimated age and the degree of dental attrition, with $r=0.94$ in males, $r=0.68$ in females, and $r=0.84$ in males-females combined. It may safely 
Table 2. Results of attritional condition according to Tochihara's classification.

\begin{tabular}{|c|c|c|c|c|c|}
\hline \multirow[b]{3}{*}{ IDNO* } & \multicolumn{5}{|c|}{ Degree of dental attrition } \\
\hline & \multicolumn{2}{|c|}{ Upper } & \multicolumn{2}{|c|}{ Lower } & \multirow{2}{*}{$\frac{\text { Total }}{\text { Average }}$} \\
\hline & r. & 1. & r. & 1. & \\
\hline $\mathrm{K}-5 \mathrm{~F}$ & 5.0 & - & 5.0 & 5.0 & 5.0 \\
\hline $\mathrm{K}-13 \mathrm{M}$ & 2.5 & 2.0 & 1.7 & 2.1 & 2.1 \\
\hline $\mathrm{K}-35 \mathrm{M}$ & 2.3 & 2.3 & 1.9 & 2.5 & 2.3 \\
\hline $\mathrm{K}-56 \mathrm{~F}$ & 4.8 & 4.5 & 4.7 & 4.7 & 4.7 \\
\hline $\mathrm{K}-64 \mathrm{M}$ & 5.5 & 5.7 & 5.6 & 5.3 & 5.4 \\
\hline $\mathrm{K}-72 \mathrm{~F}$ & 5.6 & 6.0 & 5.6 & 5.8 & 5.8 \\
\hline K-79M & 2.6 & 2.9 & 2.8 & 2.8 & 2.8 \\
\hline $\mathrm{K}-83 \mathrm{~F}$ & 5.0 & 5.0 & 4.3 & 3.8 & 4.6 \\
\hline $\mathrm{K}-89 \mathrm{~F}$ & 5.0 & 5.0 & 5.8 & 6.0 & 5.5 \\
\hline $\mathrm{K}-130 \mathrm{~F}$ & 4.6 & 4.2 & 4.7 & 4.7 & 4.6 \\
\hline $\mathrm{K}-140 \mathrm{~F}$ & 4.3 & 4.5 & 4.4 & 4.2 & 4.4 \\
\hline $\mathrm{K}-141 \mathrm{M}$ & 5.6 & 5.3 & 7.0 & 7.0 & 6.3 \\
\hline K-169M & 5.0 & - & 5.0 & 5.0 & 5.0 \\
\hline K-175M & 3.3 & 3.8 & 2.9 & 3.1 & 3.3 \\
\hline K-189F & 3.2 & 2.8 & 4.3 & 4.0 & 3.6 \\
\hline $\mathrm{K}-215 \mathrm{M}$ & 1.5 & 2.7 & 1.8 & 1.8 & 2.0 \\
\hline K-272F & 5.0 & 5.0 & 5.0 & 4.8 & 5.0 \\
\hline K-277M & 4.8 & 5.0 & 4.4 & 4.3 & 4.7 \\
\hline $\mathrm{K}-282 \mathrm{~F}$ & 5.0 & 4.3 & 4.5 & 3.0 & 4.3 \\
\hline $\mathrm{K}-285 \mathrm{~F}$ & 4.2 & 4.2 & 4.0 & 4.0 & 4.1 \\
\hline K-288M & 4.9 & 4.3 & 4.9 & 4.6 & 4.7 \\
\hline K-294F & 1.2 & 1.9 & 1.2 & 2.0 & 1.6 \\
\hline $\mathrm{K}-350 \mathrm{~F}$ & 6.0 & 3.7 & 6.0 & 6.0 & 5.5 \\
\hline $\mathrm{K}-352 \mathrm{~F}$ & 4.6 & 4.8 & 5.0 & 5.2 & 4.9 \\
\hline $\mathrm{K}-355 \mathrm{M}$ & 5.0 & 5.0 & 4.8 & 4.8 & 4.9 \\
\hline K-362M & 5.8 & 5.7 & 6.0 & 6.0 & 5.9 \\
\hline
\end{tabular}

* Identification number follows the excavation report by Nakahashi et al. (1985).

K: Kanenokuma, M: male, F: female.

be said that the rate of increase well corresponds to the estimation of age at death. From the comparison with modern Japanese (Fig. 3), it was found that, in the ca. 20-29 year-old-age range, there was hardly any difference between the degree of dental attrition of the Kanenokuma Yayoi population and that of modern Japanese. In and after the ca. 30-39 year-old-age range, there were great differences between them. It seems that it is mostly caused by dietary influences in which the Kanenokuma Yayoi population probably ate provisions tougher than those of modern Japanese, as did the prehistoric men elsewhere in the world. 


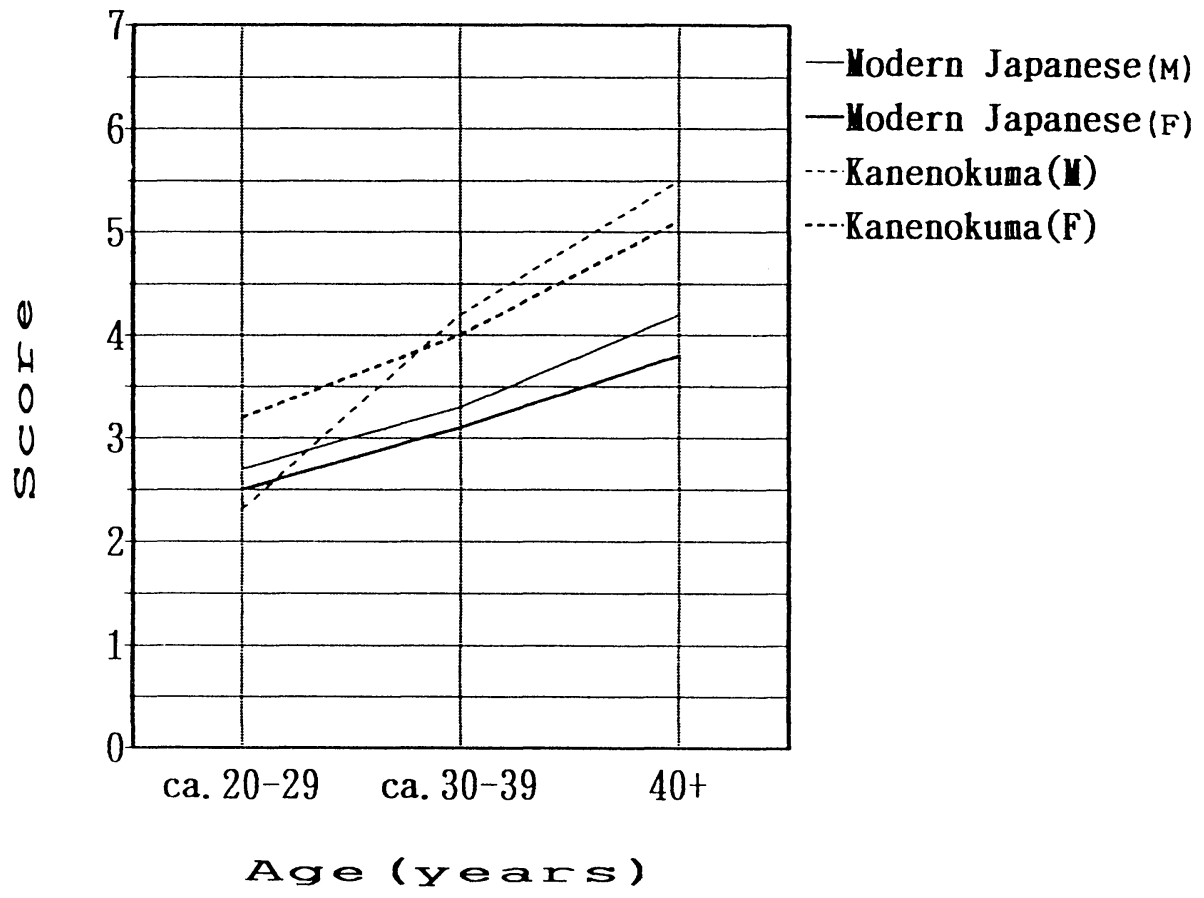

Fig. 3. Relationship between the age and the degree of dental attrition in modern Japanese (M), modern Japanese (F), Kanenokuma population (M) and Kanenokuma population (F), respectively. Data of modern Japanese were cited from Tochihara (1957).

\section{CONCLUSIONS}

In general, the degree of dental attrition of the prehistoric men is stronger than that of moderns, and the present study on the Kanenokuma Yayoi population showed the same tendency. It became clear that the progression of the degree of dental attrition had a close relation to the age of the specimens.

In Japan, this field of study has not been developed and used as yet. However, when a site has plenty of skeletal remains and the scale of the degree of dental attrition is also assessed, the degree of dental attrition may be used as a supplementary indicator of age at death even in Japanese populations of the Yayoi period.

\section{ACKNOWLEDGEMENTS}

I am grateful to Prof. Y. Shibata, Dr. T. Nakahashi and Dr. N. Doi of the Department of Anatomy, Faculty of Medicine, Kyushu University for their permission to study the materials under their care. Prof. T. Nishitani, Associate Prof. H. Okamura and Associate Prof. Y. Tanaka of the Department of Archaeology, Kyushu 


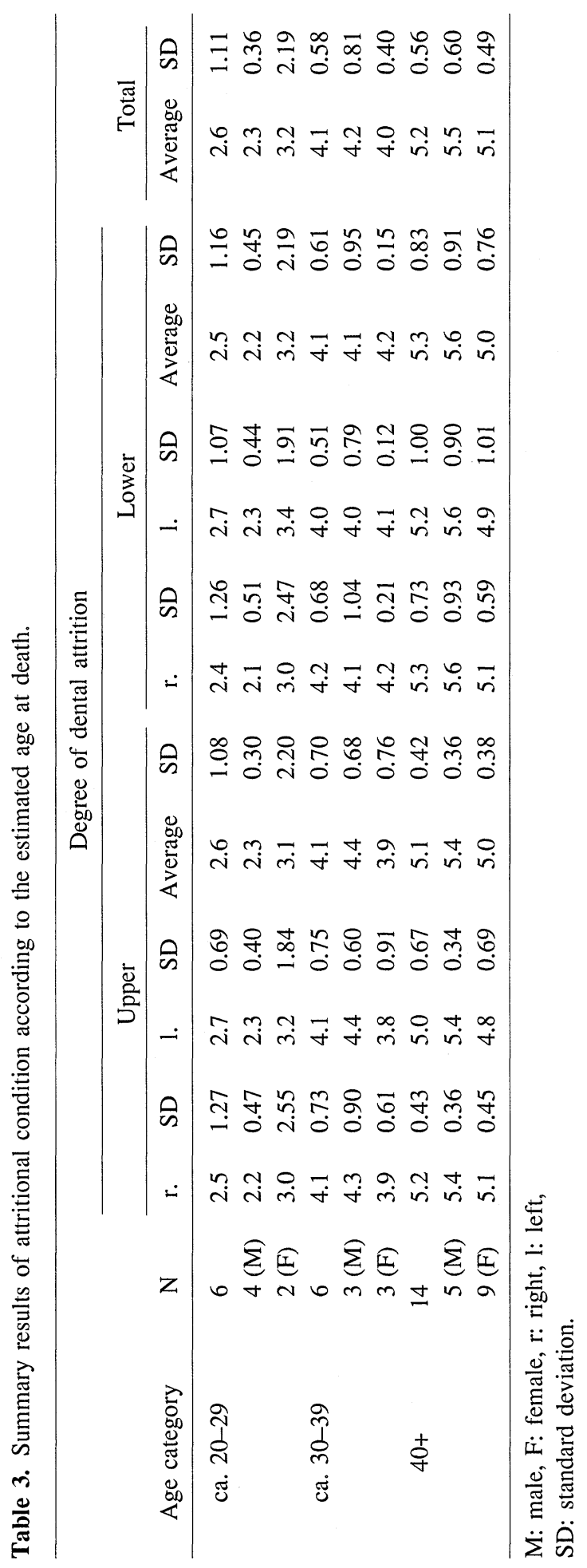


University also provided me with useful suggestions. I would also like to express my thanks to Miss C. Kumakura of the Inst. of Human Living Sciences, Otsuma Women's University for her assistance in doing statistical analysis. Finally, I give my sincere appreciation to Dr. T. Suzuki and Mr. S. Narasaki of the Department of Epidemiology, Tokyo Metropolitan Institute of Gerontology, who read the manuscript and gave me valuable comments and constant encouragement of this study.

\section{REFERENCES}

Campbell, T. D. (1939) Food, food values and food habits of the Australian Aborigines in relation to their dental conditions. Aust. J. Dent., Melbourne 43, 45-55.

Dobrovsky, M. (1946) Abrasiones dentorias en cráneos de Indios Patagones. Rev. Mus. La Plata (new style, Secc. Anthropologia) 2, 301-347.

Hada, N. (1936) Study on the relationship between dental attrition and the age in Chinese. J. Nippon Dent. Assoc. 29(3), 15-18. (In Japanese)

Hanihara, K. (1952) Age change in male Japanese pubic bone. J. Anthrop. Soc. Nippon 62, 245-260.

Hojo, M. (1954) On the pattern of the dental abrasion. Okajimas Folia Anatomica Japonica 26, 11-30.

Lovejoy, C. O. (1985) Dental wear in the Libben population: Its functional pattern and role in the determination of adult skeletal age at death. Am. J. Phys. Anthrop. 68, 47-56.

Lovejoy, C. O., Meindl, R. S., Mensforth, R. P., and Barton, T. J.(1985a) Multifactorial determination of skeletal age at death: A method and blind tests of its accuracy. Am. J. Phys. Anthropol. 68, $1-14$.

Lovejoy, C. O., Meindl, R. S., Pryzbeck, T. R., and Mensforth, R. P. (1985b) Chronological metamorphosis of the auricular surface of the ilium: A new method for the determination of adult skeletal age at death. Am. J. Phys. Anthropol. 68, 15-28.

Mckern, T. W., and T. D. Stewart. (1957) Skeletal Age Changes in Young American Males. Massachusetts Quartermaster Research and Development Command Technical Report EP-45.

Meindl, R. S., and Lovejoy, C. O. (1985) Ectocranial suture closure: A revised method for the determination of skeletal age at death based on the lateral-anterior sutures. Am. J. Phys. Anthropol. 68, 57-66.

Meindl, R. S., Lovejoy, C. O., and Mensforth, R. P. (1985) A revised method of age determination using the os pubis, with a review and tests of accuracy of other current methods of pubic symphyseal aging. Am. J. Phys. Anthropol. 68, 29-45.

Miles, A. E. W. (1963) Dentition in the estimation of age. J. Dent. Res. 42, 255-263.

Nagai, M. (1970) Study on the human skeletal remains from Kanenokuma site. In The First Excavation Report on Kanenokuma Site, Fukuoka-shi Maizoubunkazai Chosa Houkokusho Dai 7 Shu, Fukuoka-shi Kyoikuiinkai, Fukuoka. (In Japanese)

Nagai, M. (1971) Study on the human skeletal remains from Kanenokuma site. In The Second Excavation Report on Kanenokuma Site, Fukuoka-shi Maizoubunkazai Chosa Houkokusho Dai 17 Shu, Fukuoka-shi Kyoikuiinkai, Fukuoka. (In Japanese)

Nakahashi, T., N. Doi and M. Nagai. (1985) Human skeletal remains of the Yayoi period from the Kanenokuma site. In Shiseki Kanenokuma Iseki, Fukuoka-shi Kyoikuiinkai, Fukuoka, pp. 43-145. 
(In Japanese)

Pederson, P. O. (1952) Some dental aspects of anthropology. Dent. Res., London 72, 170-178.

Takei, T., Maruyama, T., Takahashi, T., Zaha, H., Yonashiro, T., and Nemoto. M. (1981) The use tooth attrition in age estimation (Part 2). Jap. J. Legal Med. 35(6), 400-410. (In Japanese with English summary)

Tochihara, H. (1957) A study on the dental attrition of Japanese. Kumamoto Igakukai Zasshi 31, 607-656. (In Japanese)

Tsuda, M. (1952) The change of the dental attrition according to the age (Abstract). Shika Igaku 15(1), 126. (In Japanese)

Ubelaker, D. H. (1989) Dental development: Estimating age at death. In Human Skeletal Remains: Analysis, Interpretation, 2nd Ed., Taraxacum, Washington, pp. 63-65.

Yamada, E. (1932) Study on the relationship between dental attrition and the age in Japanese. J. Nippon Dental Assoc. 25(11), 76-88. (In Japanese)

Yoshida, H. (1976) On the correlation among the human teeth concerning the attrition. Nihon Univ. Dent. J. 50, 757-765. (In Japanese with English summary)

Zuhrt, R. (1955) Stomatologische Üntersuchungen an Spätmittelterlichen Funden von Reckkahn. (12-14Jh.) I. Die Zahnkaries und ihre Folgen. Dtsche Zahn-, Munds-, und Kieferheilkunds 25, $1-15$. 